\title{
Correction to: Interaction dynamics between a contaminated dredged sediment and extracting solutions of different nature
}

\author{
Nieves Garcia-Blas ${ }^{1,2} \cdot$ Eva Jimenez-Relinque $^{1} \cdot$ Roman Nevshupa $^{1} \cdot$ Marta Castellote $^{1}$ (i)
}

Published online: 7 February 2020

(C) Springer-Verlag GmbH Germany, part of Springer Nature 2020

\section{Correction to: Journal of Soils and Sediments https://doi.org/10.1007/s11368-019-02466-5}

Figure 4 is not correct in the PDF format of the originally published article. Please note that in the HTML or online format, the image is correct.

Correct figure is given below.

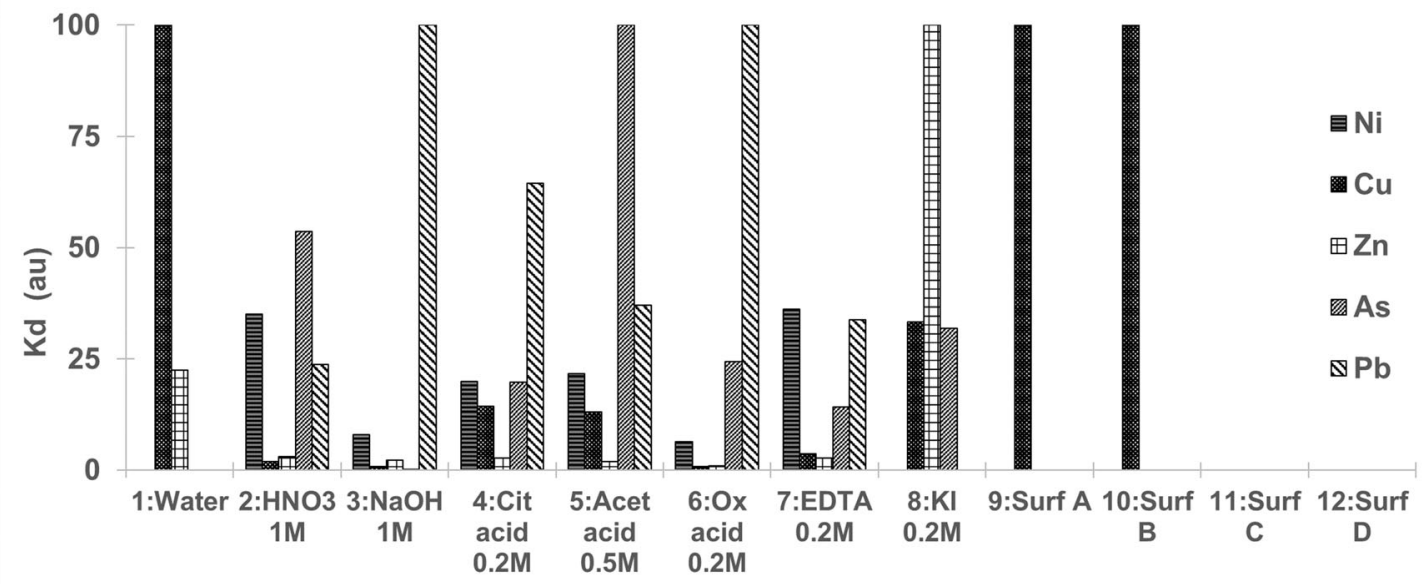

Fig. 4 Normalized $K_{d}$ (in arbitrary units) for each solution. Missing bars in the graph mean that the value of the metal in the solution was below the limit of detection of the analytical technique

The original article has been corrected.

The online version of the original article can be found at https://doi.org/ 10.1007/s11368-019-02466-5

Marta Castellote

martaca@ietcc.csic.es

1 Institute of Construction Science Eduardo Torroja (IETcc-CSIC),

Serrano Galvache 4, 28033 Madrid, Spain

2 National Distance Education University (UNED), Madrid, Spain 